Discussion Paper No. 695

\title{
KOIZUMI CARRIED THE DAY: \\ DID THE JAPANESE ELECTION RESULTS \\ MAKE PEOPLE HAPPY AND UNHAPPY?
}

\author{
Yoshiro Tsutsui \\ Miles Kimball \\ and \\ Fumio Ohtake
}

July 2007

The Institute of Social and Economic Research

Osaka University

6-1 Mihogaoka, Ibaraki, Osaka 567-0047, Japan 


\title{
Koizumi Carried the Day:
}

\section{Did the Japanese Election Results \\ Make People Happy and Unhappy?*}

\author{
Yoshiro Tsutsui (Osaka University) \\ Miles Kimball (University of Michigan) \\ Fumio Ohtake (Osaka University)
}

\section{Correspondence:}

Yoshiro Tsutsui,

Institute of Social and Economic Research,

Osaka University

6-1 Mihogaoka,

Ibaraki 567-0047, Japan.

Phone: +81-6-6879-8560

Fax: +81-6-6878-2766

E-mail: tsutsui@econ.osaka-u.ac.jp

\footnotetext{
* An earlier version of this paper was presented at the conference of behavioral economics held in Kyoto, Annual meetings of Japanese Economic Association and The Japan Society of Household Economics. The authors are grateful to Daiji Kawaguchi, Fumihiko Hiruma, and the participants for their comments. The study is financially supported by the $21^{\text {st }}$ century COE program funded by the Ministry of Education, Culture, Sports, Science and Technology.
} 


\begin{abstract}
This paper investigates whether Japanese people were happy and unhappy with the general election conducted on September 11, 2005, in which the Prime Minister, Koizumi, won a landslide victory. We conducted a large survey just after the election to ask people how happy they were and which party they had supported. Although there are consistent tendencies that supporters of ruling parties were happier and supporters of opposition parties were unhappier, the effect was not significant. Considering the results of a previous study that showed that Americans demonstrated significant responses to the result of a presidential election, this study suggests that Japanese people are indifferent to politics.
\end{abstract}

Keywords: election, happiness, Koizumi Cabinet, survey, Japan

JEL classification number: I31, D72, C42 


\section{Introduction}

To what extent are people interested in politics? Standard economic theory assumes that people's utility depends on their own consumption, and so the importance of political institutions is often disregarded, although the latter essentially determine overall economic outcomes. Of course, people admit that the political system is an infrastructure necessary to achieve high economic performance and is very important from the view point of improving the level of happiness of people (Frey and Stutzer, 2002).

Nevertheless, many people do not participate in political activities because the political system is seen as a public good that can be free-ridden. On the other hand, the political process can be regarded as a battle between two competing opinions rather than the provision of public goods. However, even in this case, people tend to think that they are too small and helpless to influence the outcome, and so they do not participate in political activities. This is also a kind of a free-rider problem within a political group. In fact, the voting rate has been declining in many countries, including Japan and the U.S., and indifference to politics is an important social problem in democratic countries.

This paper investigates whether Japanese people were happy and unhappy with the election outcomes. Although democratic countries worry about their nations' indifference to politics, there are no good ways to measure the degree of interest in an election amongst a nation's population. Asking people about their happiness after an election and comparing the levels of happiness of winners and losers may be a good method to measure their interest in an election; people who are interested in victory or defeat in an election should become happy or unhappy with the results. Nevertheless, there have been only a few studies, to our knowledge, that have investigated the degree 
of happiness amongst voters (Wilson et al., 2003 and Gilbert et al., 1998). These previous studies asked only 52 and 57 voters respectively; therefore, these results cannot be seen as a convincingly robust representation of any tendency in the United States. We conducted a large survey in which we obtained about 1400 responses every month, randomly sampled from all over Japan. Thus, this is the first comprehensive study to investigate how much people are interested in an election.

Our study is also unique from the viewpoint of studying the degree of happiness with results. Most of the surveys on happiness ask people about their overall feeling of happiness. ${ }^{1}$ The typical question is Overall, to what degree are you currently feeling happy? This type of question neglects an important characteristic of the feeling of happiness, i.e., that it fluctuates in line with news and personal events (Kimball and Willis, 2006). In contrast, this study focuses on how people's happiness is influenced by macro news such as election results. In order to investigate how happiness depends on news and personal events, we conducted a survey on happiness every month with respondents in Japan and asked them about their current feeling. ${ }^{2}$

In this paper, we analyze the effect of the general election conducted on September 11, 2005. This election was a rather heated one and the Koizumi Cabinet won an overwhelming victory that exceeded predictions by the media. Surprisingly, our study does not find any significant change in happiness amongst winners or losers, suggesting that Japanese people are indifferent to politics.

This paper is organized as follows. In the next section, we first explain how the election was conducted and provide an outline of our survey. Then, we show that there

\footnotetext{
${ }^{1}$ Kahneman et al. (2004) is a notable exception. They asked 900 working women on their change in happiness during the course of a day.

${ }^{2}$ We conducted a similar survey in the U.S., from which we found that Hurricane Katrina made Americans significantly unhappy. See Kimball et al. (2006).
} 
is a tendency for supporters of ruling parties to become happier and for those of opposition parties to become unhappier, but that this tendency is insignificant. In section 3, by looking at the level of happiness over the six days following the election, we examine how the elation and dismay at the result of the election faded away. In section 4, we analyze the happiness of cabinet supporters. In section 5, we examine whether the happiness of voters was affected by the win or loss of their candidates. Section 6 is devoted to discussion of our findings and conclusions that can be drawn from them.

\section{Did Japanese become happy and unhappy according to their political} allegiance?

\subsection{The general election on September 11, 2005}

The general election was conducted on Sunday, September 11, 2005, and the Prime Minister, Koizumi, won a landslide victory. The Liberal Democratic Party (hereafter LDP) carried 296 seats of the 480 seats in the House of Representatives. Combining these with the seats carried by New Komeito (Komei), with which the LDP has concluded an alliance, the ruling parties carried over $2 / 3(327 / 480)$ of the seats in the House of Representatives. The Japanese Diet consists of the House of Representatives and the House of Councilors, and to be approved, bills should clear both. However, even if they are rejected in the House of Councilors after approval by the House of Representatives, they are approved if they win over $2 / 3$ of the votes in the House of Representatives on a second vote. Therefore, the victory of over $2 / 3$ of the seats in the House of Representatives implies that Prime Minister Koizumi can pass any bill that he wants. 
To understand why this election result is important, we need to explain the situation under which Koizumi dissolved the House of Representatives on August 8. The alliance of the LDP and Komei commanded a majority in both Houses; therefore, in principle, they could have passed any bill. However, the privatization of the Japan Postal Service Public Corporation, which was the most important public promise made by Koizumi, met strong opposition from many Diet members of the LDP. In consequence, the bill passed the House of Representatives by a close margin, but was rejected in the House of Councilors on August 8. Prime Minister Koizumi dissolved the House of Representatives at once, saying that he wanted to ask the nation's opinion on the privatization. Thus, the general election became a kind of national referendum on the policy of the reform of postal services. How this election attracted the nation's attention was reflected in the high turnout rate of voters: $68 \%$ this time around, as against $60 \%$ at the last general election. The main events reported in newspapers during the period from August to October can be found in the Appendix.

\subsection{Our survey}

We conducted monthly surveys from August 2005 to February 2006, and focused on the impact of the general election conducted on September 11, 2005.

Let us explain the outline of our survey, taking the September survey as an example. The surveys in the other months have similar features. In each case, 2000 people over 20 years old were randomly selected from all over Japan and interviewed. ${ }^{3}$ In the September survey, the number of effective responses was 1399; the response rate was $70.0 \%$. The survey was conducted from September 13 to 20 , and the number of

\footnotetext{
${ }^{3}$ The survey is not a panel. Different people are randomly chosen every time.
} 
respondents on each date is shown in Table $1 .^{4}$

653 respondents (46.7\%) were male and $746(53.3 \%)$ were female. In terms of age, $10.4 \%$ were $20-29$ years old, $18 \%$ were $30-39$ years old, $17 \%$ were $40-49$ years old, $22 \%$ were 50-59 years old, and 33\% were over 60 years old. As for academic background, $15 \%$ had been to a grade school, $52 \%$ had a high school education, and $32 \%$ had been to an university. We also have the data on their household income, occupation, residence location, and the size of cities, as well as their attitude towards the Koizumi Cabinet, which party they support, and their view on the state of business. ${ }^{5}$

749 respondents $(53.5 \%)$ supported the Koizumi Cabinet, 416 (29.7\%) were opposed to it, and $234(16.7 \%)$ answered "do not know." The parties supported by respondents are shown in Table 2. 32\% supported the LDP and 15\% supported the Democratic Party of Japan (DP), while $42 \%$ did not support any party. Thus, how to attract those who did not support a specific party was the key, and according to exit polls, about a half of them voted for the LDP, leading to the victory of Koizumi.

As for happiness, the following question was asked:

Please remember how you felt in this one week. To what degree were you feeling happy in the last week? On a scale of $0-10$, where " 10 " is "very happy" and " 0 " is "very unhappy," how do you rate your level of happiness in the last week?

We define a variable, Happiness, for this value. The results of the survey conducted in September are shown in Table 3. Out of 1399, those who chose 5 formed the largest group $(397=28.4 \%)$, and those who chose 6,7 , or 8 numbered over 200 each (about $15 \%)$. The average happiness value was $6.3 .^{6}$

\footnotetext{
${ }^{4}$ Although one answer and four answers were obtained on September 13 and 20, respectively, we disregard them when analyzing the effect on each day because they are very few in number.

${ }^{5}$ Household income has not been asked in the surveys for several months.

${ }^{6}$ A similar question about overall happiness has been asked in the "survey of preference on life
} 


\subsection{Level of happiness of Supporters of ruling parties}

We want to investigate whether the level of happiness of supporters of the ruling parties rose from August to September, and whether the degree of happiness of supporters of opposition parties fell during the same period. In this subsection, we calculate the averages of happiness for these groups for each month in order to compare them. Since happiness changes from month to month due to various reasons, we must be careful to adjust the figures to allow for this variation caused by events other than the election.

As can be seen from Figure 1, the average happiness of all respondents substantially varied over the period. In particular, we are interested in the change in happiness from August to September and the figures show that the average level of happiness of all respondents in August is higher than that in September. Thus, if we find a decrease in happiness amongst supporters of the ruling parties in September, it does not necessarily imply that the election results affected the supporters in a negative way. In order to identify the effect of the election results on the level of happiness amongst supporters of the ruling and opposition parties, it is necessary to adjust the change in average happiness between months. To do so, we divide the happiness of supporters of ruling and opposition parties by the average happiness of all respondents for each month.

Indeed, happiness amongst supporters of the ruling parties in September was lower than that in August. However, when we adjust the change in average happiness of all respondents, the outcome is reversed. The dark color columns in Figure 2, which represent the level of normalized happiness, reveal that supporters of the ruling parties in Japan.” The results (the average and distribution) are quite similar. 
rose in September, declined until December, and rose again in January and February. The rise in September may be due to the victory in the election.

The grey color columns in Figure 2 represent the normalized happiness of supporters of opposition parties. The normalized happiness fell in September, fell even more in October before going up until January. ${ }^{7}$ The result that the level of happiness fell in September is consistent with the notion that it was caused by the defeat in the election. However, one may argue that the result that it fell more in October than in September makes this an unreasonable explanation.

Our survey also asks whether or not people support the Koizumi Cabinet. According to the results, a large proportion of supporters of opposition parties also supported the Koizumi Cabinet in September. This is not strange because the Prime Minister, Koizumi, claims that he is the real reformer of the LDP, and so people who are against the LDP may, nonetheless, support Koizumi. They may have felt happy to hear that Koizumi won.

Considering this fact, it may be appropriate to focus on the happiness of those who supported the opposition and did not support the Koizumi Cabinet. The light color columns in Figure 2 represent the results, which reveal that the happiness of those people fell in September and rose in October, and then continued to go up until December. This result is consistent with the supposition that people who were against both Koizumi and the LDP became unhappy with the defeat in the general election in September, 2005.

The ruling party consists of the LDP and Komei, while the opposition consists of the Democratic Party of Japan (DP), the Japanese Communist Party (Communist), the

\footnotetext{
${ }^{7}$ Original happiness of supporters of opposition parties before normalization fell in September.
} 
Social Democratic Party (SDP), the People's New Party (PNP), and New Party Nippon (NPN). Let us examine whether the results on ruling and opposition parties mentioned above apply for each party. The supporters of Communist, SDP, PNP, and NPN are too few to get reliable statistics for each party; therefore, we aggregated the supporters of these small parties into one group (SMALL) and considered the LDP, Komei, DP, and SMALL.

The dark color columns in Figure 3 show the results for the LDP. The level of happiness rose in September. However, the difference from August to September was only 0.004 and the happiness rose more in October. Thus, the rise in happiness of LDP supporters was small in September.

The light color columns in Figure 3 show the results for Komei. The level of happiness rose in September and fell in October. The difference from August to September is 0.04 , which is ten times larger than that of supporters of the LDP. Thus, the rise in happiness of Komei (the smaller ruling party) supporters is more pronounced than that of LDP (the larger ruling party) supporters.

The dark color columns in Figure 4 show the results for the DP. The level of happiness fell in September and rose in October. However, the difference from August to September was only 0.001 .

The grey color columns in Figure 4 show the results for SMALL, i.e., Communist, SDP, NPN, and PNP taken together. The level of happiness fell in September. The difference from August was 0.04, which is forty times larger than that for the DP. Thus, the fall in happiness of SMALL's supporters was more pronounced than that of DP's supporters. Considering the results for the LDP and Komei together, these results suggest that the supporters of smaller parties were more strongly affected by the results 
of the election.

However, the result that the level of happiness dropped much more in October than in September is strange. This may be due to the fact that a considerable proportion of the supporters of opposition parties also supported the Koizumi Cabinet. For example, among the 32 supporters of Communist in September, 19 did not support the Cabinet and ten did support the Cabinet. ${ }^{8}$ The average happiness of the former group was 5.2, while that of the latter was 8.0. Thus, in September, the anti-cabinet Communist supporters were much unhappier than pro-cabinet Communist supporters.

To get rid of the bias from pro-cabinet supporters of opposition parties, we show the happiness of supporters of SMALL who were anti-cabinet as the light color columns in Figure 4. Their level of happiness fell in September by almost 0.10. While the happiness was lower in October than in September, the change between September and October was only half that between August and September.

The results in Figures 2-4 suggest that the supporters of ruling parties felt relatively happy in September than in August, while those of opposition parties felt less happy in September than in August. Considering that the survey was conducted a few days after the election, the landslide victory of Koizumi may be the cause of this rise and fall in happiness. The effect was larger for the supporters of smaller parties; for ruling parties, the effect on Komei was larger than that on the LDP, and for the opposition parties, the effect on SMALL was larger than that on the DP.

\subsection{Is the change significant?}

In this subsection, we examine whether the rise and fall in the level of happiness in

\footnotetext{
${ }^{8}$ Three answered 'do not know'.
} 
September is significant. To test the significance of the change in happiness of supporters of the ruling parties, we estimate the following equation. ${ }^{9}$

$$
\begin{aligned}
\text { Happiness }_{i}= & \alpha_{1}+\alpha_{2} \text { SEP }_{i} \times D R U L E_{i}+\alpha_{3} \mathrm{OCT}_{i} \times D_{R U L E_{i}}+\alpha_{4} N O V_{i} \times D R U L E_{i} \\
& +\alpha_{5} D E C_{i} \times D R U L E_{i}+\alpha_{6} J A N_{i} \times D R U L E_{i}+\alpha_{7} F E B_{i} \times D R U L E_{i} \\
& +\beta_{1} D R U L E_{i}+\beta_{2} S E P_{i}+\beta_{3} O C T_{i}+\beta_{4} N O V_{i}+\beta_{5} D E C_{i}+\beta_{6} J A N_{i}+\beta_{7} F E B_{i}
\end{aligned}
$$

where $A U G, S E P, O C T, N O V, D E C, J A N$, and FEB are dummy variables standing for each month. DRULE is a dummy variable, which is 1 if the respondent is a supporter of ruling parties and 0 otherwise. Subscript $i$ stands for the respondents from August to February $(i=1, \ldots, 8592)$. The change in happiness of supporters of ruling parties from August to September is measured by the coefficient of SEP $\times$ DRULE, $\alpha_{2}$.

The estimates of (1) are shown in Table 4, which reveal that average happiness in September is significantly lower (at the $5 \%$ level) than that in August (see SEP). ${ }^{10}$ Supporters of the ruling parties are significantly happier (at the 5\% level) than others (see DRULE). The supporters of the ruling parties were happier in September than in August, but this is not significant (p-value is 0.315 , see DRULE*SEP). However, the coefficient is larger and more significant than those of other months, suggesting that this coefficient may reflect the impact of the election.

We estimate equations similar to (1) for the supporters of opposition parties, SMALL (Communist, SDP, NPN, and PNP), LDP, and Komei. ${ }^{11}$ In order to save space, only the estimates of $\alpha_{2}$ are presented in Table 5. The indicators are consistent with our expectation in all cases: those belonging to ruling parties, LDP, and Komei, are positive, while those belonging to opposition parties, SMALL, and SMALL cum anti-cabinet, are negative. This suggests that the results may not be accidental. However,

\footnotetext{
${ }^{9}$ Alternatively, we could test the mean difference of the normalized happiness in August and September.

${ }_{10}$ The average happiness is also significantly lower in February.

11 DRULE in equation (1) is replaced with corresponding dummy variables.
} 
the estimates are all insignificant, suggesting that the effect of political events on the happiness of the Japanese was quite limited, if it existed at all. The coefficient is larger for Komei and SMALL (cum non-cabinet supporter) compared with the LDP and the opposition parties in total, suggesting that the supporters of smaller parties like Komei, Communist, and SDP have stronger loyalty than supporters of larger parties like the LDP and DP. ${ }^{12}$

\section{Daily change in happiness in September}

Happiness of supporters of political parties varies over a period of months, as shown in Figures 2-4. However, it is not likely that the effect of the election results on the happiness of average Japanese people lasts over months. The effect, if it exists, should fade away in a shorter period. Kimball et al. (2006) showed that Hurricane Katrina made American people unhappier, but the effect faded away within a week. In this section, we investigate, by looking at the daily data, how long the effect of the election lasted.

The survey was conducted from September 13 to 20. The number of respondents on each date, shown in Table 1, varies from 150 to 350 , with the exception of September 13 and $20 .{ }^{13}$

We calculate average happiness of supporters of ruling parties each day. Since happiness possibly fluctuated in line with macro news every day, we divide the average by the mean of happiness of all respondents for each day. No specific trend is observed (figure is not shown in order to save space).

12 These estimates are not significant, probably because the number of supporters is small.

13 Although one answer and four answers were obtained on September 13 and 20, respectively, we disregard them when we analyze the effect for each day because they are very few in number. 
The results of the supporters of Komei are represented by the dark color columns in Figure 5. The average happiness declined from September 14 to 16, while the trend thereafter is unclear.

The light color columns in Figure 5 represent the results of opposition parties. ${ }^{14}$ The level of happiness rose from September 14 to 17 and thereafter declined. These two results in Figure 5 may suggest that the effect of the election results lasted until September 16 or 17.

To examine if this change in happiness by day is significant, we estimate the following equation:

$$
\begin{aligned}
\text { Happiness }_{i}= & a_{0}+a_{1} D A Y 15_{i}+a_{2} D A Y 16_{i}+a_{3} D A Y 17_{i}+a_{4} D A Y 18_{i}+a_{5} D A Y 19_{i} \\
& +b_{0} D R U L E_{i}+b_{1} D R U L E_{i} \times D A Y 15_{i}+b_{2} D R U L E_{i} \times D A Y 16_{i} \\
& +b_{3} D R U L E_{i} \times D A Y 17_{i}+b_{4} D R U L E_{i} \times D A Y 18_{i}+b_{5} D R U L E_{i} \times D A Y 19_{i}
\end{aligned}
$$

where DAY15 stands for a dummy variable for September 15 and so on. $i$ stands for respondents of the September survey $(i=1, \ldots, 1361) . \quad b_{1}$ represents the discrepancy in happiness of supporters of ruling parties between September 15 and 14. The coefficients $b_{1}-b_{5}$ are not significant (results are not shown). The coefficients for supporters of Komei and opposition parties are not significant either. Therefore, the day-effect in Figure 5 is weak, if it exists.

\section{Happiness of cabinet supporters}

Who carried the day; the LDP or Koizumi? This is the question asked by the media after the election. The answer was Koizumi. It may be interesting to see if the cabinet supporters were happier than supporters of each party in September.

\footnotetext{
${ }^{14}$ We expected that the happiness of supporters of SMALL would show a clearer pattern. Unfortunately, the analysis of "smaller opposition parties" is impossible because the observations are too few in number.
} 
The dark color columns in Figure 6 represent the average happiness of cabinet supporters in each month divided by the average happiness of all respondents for each month. ${ }^{15}$ Unexpectedly, the normalized happiness of cabinet supporters declined in September. The grey color columns in Figure 6 represent the happiness of anti-cabinet supporters. Their happiness also declined in September. These results mean that only those who answered "do not know" were happier in September, as shown by the light color columns in Figure 6.

Why did this happen? There are two key facts to consider. The first is that the number of cabinet supporters increased from 549 in August to 733 in September (see Table 6). The other is that cabinet supporters are always happier than anti-cabinet supporters; 6.62 as against 6.20 in August. Given these facts, a possible explanation for the fall of happiness of pro-cabinet supporters is as follows. The increase in the number of pro-cabinet supporters means that many people who would not have been pro-cabinet in September, if the exogenous factors such as occurrence of the general election had been the same as in August, actually changed their opinion to pro-cabinet. Since non-pro-cabinet are generally unhappier than pro-cabinet, this shift produces a downward bias of happiness of cabinet supporters in September. In short, the number of people who support the cabinet is endogenously determined and an increase in their number implies the inclusion of unhappier people into this category.

Thus, to measure the effect of the victory in the election on the level of happiness amongst pro-cabinet supporters, we need to identify imaginary cabinet supporters in September who were also pro-cabinet in August. Since the survey chooses different random samples every month and our sample is not panel data, we need to estimate

${ }^{15}$ Cabinet supporters are consistently happier than anti-cabinet supporters. 
hypothesized pro-cabinet supporters.

To solve this problem, we first estimate a model that explains what type of people tend to support the Koizumi Cabinet. Adopting all the information available in our survey, we estimate the following equation:

$$
\begin{aligned}
\text { DCAB }_{i} & =a_{0}+a_{1} \text { GOODNEWS }_{i}+a_{2} \text { DMAN }_{i}+a_{3} \text { AGE }_{i}+a_{4} \text { SCHOOL }_{i}+a_{5} \text { LARGE15CITY }_{i} \\
& +a_{6} \text { OTHERCITY }_{i}+a_{7} \text { AGRICULTURE }_{i}+a_{8} \text { FIELD }_{i}+a_{9} \text { FREE__MANAGE }_{i} \\
& +a_{10} \text { HOUSEWIFE }_{i}+a_{11} \text { STUDENT }_{i}+a_{12} \text { OTHERJOB }_{i}+a_{13} \text { HOKKAIDO }_{i} \\
& +a_{14} \text { TOHOKU }_{i}+a_{15} \text { KANTO }_{i}+a_{16} \text { KEIHIN }_{i}+a_{17} \text { KOSHINETSU }_{i} \\
& +a_{18} \text { HOKURIKU }_{i}+a_{19} \text { TOKAI }_{i}+a_{20} \text { KINKI }_{i}+a_{21} \text { HANSHIN }_{i} \\
& +a_{22} \text { TYUGOKU }_{i}+a_{23} \text { SHIKOKU }_{i}+a_{24} \text { GOODBC }_{i} \\
& +a_{25} \text { LDP }_{i}+a_{25} \text { DP }_{i}+a_{26} \text { KOMEI }_{i}+a_{27} \text { COMMUNIST }_{i}+a_{28} \text { SDP }_{i}
\end{aligned}
$$

where $D C A B$ is a dummy variable, which is 1 when a respondent supports the Koizumi Cabinet and 0 otherwise. GOODNEWS is a variable that takes a value from 1 to 12 corresponding to the range between "they had very good personal news or event in the last week" and "they had very bad personal news or event in the last week." DMAN is a dummy variable, which is 1 when a respondent is a man and 0 otherwise. AGE is the age of each respondent, SCHOOL is a variable which takes 1 if the respondent's academic education is grade school, 2 if high school, and 3 if university. LARGE15CITY is a dummy variable that takes 1 if a respondent lives in one of the 15 largest cities in Japan and 0 otherwise. OTHERCITY is a dummy variable that takes 1 if the respondent lives in the other cities. Variables from AGRICULTURE to OTHERJOB are dummy variables that take 1 if a respondent engages in a certain occupation. Variables from HOKKAIDO to SIKOKU stand for a dummy variable representing regions in Japan. $G O O D B C$ is a variable that takes a value from 1 to 5 corresponding to "business condition definitely becomes better" to "business condition definitely becomes worse." 
Variables from SLDP to SSDP are dummy variables for supporters of each party. Subscript $i$ stands for all respondents of the whole period $(i=1, \ldots, 8592)$.

Using all the data from August to February, we estimate (3) with a probit. The estimation results are shown in Table 7. Those who have higher education, who think that business condition becomes better, and who got good personal news in the last week tend to be cabinet supporters. Some regions are significant: HOKKAIDO and KOSINETSU have negative indicators, while KEIHIN and KINKI have positive indicators. Naturally, the LDP and Komei supporters also tended to support the cabinet, whilst DP, Communist, and SDP supporters tended to be anti-cabinet.

Then, using these estimates, we construct the fitted value for each respondent, and transform it into a probability with CNORM (fitted value), where CNORM stands for the cumulative normal distribution. The number of cabinet supporters was 521 and at its lowest in August; therefore, we select the top 521 respondents based on the probability from those who answered "pro-cabinet" in the survey for each month. ${ }^{16}$

The average happiness of these 521 hypothetical pro-cabinet supporters for each month, normalized by the average happiness of all respondents for each month, is presented in Figure 7. The normalized average happiness of cabinet supporters rose in September, then declined until December, and went up thereafter. In contrast to Figure 6, happiness in September is higher than that in August. This outcome confirms that the reason why the happiness of pro-cabinet supporters declined in September is the sharp increase in pro-cabinet supporters in September who are unhappier than cabinet supporters. Once the endogeneity of cabinet supporters is adjusted by picking up the

\footnotetext{
${ }^{16}$ Alternatively, we can select the top 521 respondents disregarding the information on their answer of the pro-cabinet question. We believe, however, that the information is important, since R-squared of (3) is only 0.29 .
} 
same number of cabinet supporters, we found that their happiness rose relatively in September, suggesting that the victory in the general election was good news to pro-cabinet supporters.

Is this rise in happiness significant? To investigate this, we use equation (1), in which DRULE is substituted by $A D D C A B$ standing for a dummy variable that is 1 for 521 hypothetical cabinet supporters and 0 otherwise. The results are shown in Table 8. SEP is negative, even though insignificant at the $10 \%$ level, suggesting that happiness declined in September. $A D D C A B$ is significantly positive, suggesting that the hypothetical pro-cabinet supporters were happier than others. $A D D C A B^{*} S E P$ is positive, which suggests that the hypothetical pro-cabinet supporters were happier in September than in August; however, this value is not significant.

The insignificant results raise the doubt that the rise in September is perhaps only accidental. However, considering that all the results on the rise and fall of happiness amongst supporters of the ruling parties, the opposition parties, and the cabinet are consistent with our supposition, it may be the case that the election results really affected the happiness of the Japanese, albeit only weakly.

\section{Number of elected representatives and happiness of the inhabitants}

The prefecture where each respondent lives was documented, so that it is possible to estimate the effect of the number of winners of the LDP by prefecture in the general election on the level of happiness of the LDP supporters. ${ }^{17}$ We construct a variable, WLDP, defined as (number of winners of LDP in a prefecture where a respondent

\footnotetext{
${ }^{17}$ We also estimate the effect of the number of winners of parties other than the LDP, leading to insignificant results. There are small electoral districts and proportional electoral districts in the current Japanese electoral system. In this paper, we consider only the winners of the former districts because people are generally interested in small electoral districts.
} 
lives)/(total number of winners (i.e., seats) of the prefecture). To examine whether LDP supporters became happier with the victory of the LDP in their home prefecture, we estimate the following equation.

$$
\text { Happiness }_{i}=a_{0}+a_{1} S L D P_{i}+a_{2} S L D P_{i}^{*} W L D P_{i}
$$

where $S L D P$ is a dummy variable, which takes 1 if a respondent supports the LDP and 0 otherwise. Subscript $i$ stands for respondents in September $(i=1, \ldots, 1361)$

The estimation results are presented in the first column of Table 9. Both coefficients, $a_{1}$ and $a_{2}$, have a positive indicator, but they are not significant. Thus, it can be said that LDP supporters did not care about the results of the election in their home prefecture.

Incidentally, $S L D P$ and the cross term are significant when Happiness is regressed on them separately, implying that LDP supporters are happier than others (see the second and third columns of Table 9). WLDP is also positive when Happiness is regressed on only this variable, suggesting that the LDP won in the prefectures where a larger proportion of the inhabitants support the LDP, and they tend to be happier (see the extreme right column of Table 9).

\section{Discussion and Conclusions}

This paper examined whether the landslide victory of the Koizumi Cabinet in the general election on September 11, 2005 made Japanese people happy and unhappy.

Relative changes in happiness of supporters and non-supporters of ruling parties from August to September were not significant. However, we found that the indicators representing the effects are consistent with our expectation in most cases, which suggests that the Japanese people were only slightly happy and unhappy with the election results. 
This result seems to imply that Japanese are quite indifferent to politics. However, we need to examine a couple of elements before drawing this conclusion. Our results could possibly have been obtained, even if the Japanese were deeply commited to politics. One possibility is that the election results were anticipated beforehand, and so the historic victory of Koizumi was not really a surprise. However, according to the articles based on polls before the election, this supposition is not correct. All predictions made by newspapers underestimated the number of seats gained by ruling parties. For example, the Asahi, based on their poll (118,616 responses), reported on September 4 that the ruling parties would win 254 to 310 seats (their best estimate was 283). The Mainichi also announced their prediction on September 4, based on their poll $(90,043$ respondents), that the ruling parties would win 275 to 327 (the average is 301) seats. In fact, the ruling parties won 327 . Thus, the prediction in the media that the ruling parties would win the majority was proved correct, and so winning the majority itself was not a surprise. However, winning two thirds of the seats should have been a surprise.

In addition, one important point is that this overwhelming victory may not be good news even to the supporters of ruling parties. The majority of people thought that Koizumi (or the ruling parties) won too many seats. Interestingly, according to polls after the election, about one third of those who had voted for the LDP answered that fewer seats for the ruling parties would have been better (the Nikkei and the Yomiuri, September 14). This suggests that one third of those who voted for the LDP may not be happy because the LDP won too many seats. They may have regretted that they had voted for the LDP, suggesting that many people supported the LDP only relatively, and not absolutely. This is an example of the fallacy of composition. Considering this fact, it is not surprising that supporters of ruling parties did not become significantly happier, 
even if they were deeply interested in politics. However, the fact does not explain why supporters of opposition parties did not become significantly unhappier, even though they were not indifferent to politics. Thus, our survey results suggest that Japanese people are essentially indifferent to politics.

The next question is whether the Japanese are more indifferent to politics than people in other countries. A good measure of people's interest in politics may be the voting rate. The voting rate in the general elections in Japan has been declining over the years since the first general election in 1890 , reaching about $60 \%$ in recent years. On the other hand, the voting rate in the presidential election in the U.S. was $51 \%$ in 2000 . Thus, the voting rate is not low in Japan, at least for general elections. We should note, however, that people should register beforehand to vote in the U.S., while registration is not necessary in Japan. ${ }^{18}$ Thus, it is easier for Japanese to vote; therefore, a simple comparison may not be appropriate. ${ }^{19}$

The voting rate has been declining over the years in many countries, and so the governments of these countries warn of the crisis of democracy and try to increase the voting rate. Although they lament people's indifference to elections in their home countries, it is difficult to know which nation is more indifferent to elections because voting rates depend heavily on the electoral system.

Another barometer for interest in politics may be the number of members of political parties. The number of registered Republicans in the United States is approximately 60 million, while the number of the members of the LDP in Japan is 1.2

\footnotetext{
18 The US registration rate was $75 \%$ in 2000 .

19 In France, where people need to register to vote, the voting rate for presidential elections has been over $70 \%$ over the last 30 years. As for the parliamentary elections in France, the voting rate has been around $60 \%$ since 1988 , which implies a higher incentive for voting than applies in the Japanese case, considering the trouble of registration.
} 
million. ${ }^{20}$ The number is much smaller in Japan than in the U.S., which emphasizes that politics is more popular in the U.S. than in Japan. However, a simple comparison may lead to a fallacy, since the definition of a party member is different in the two countries. $^{21}$

The two measures, voting rate and the number of members, are vulnerable to differences between the systems and do not offer reliable evidence for comparison of people's indifference to politics. Rather, a survey on happiness of supporters of political parties like the one in this paper is expected to elucidate the degree of interest in elections.

There have been two studies that examined the effect of election results on happiness of supporters of candidates. One is Gilbert et al. (1998), which analyzed happiness amongst 57 voters at a gubernatorial election in Texas in 1994. Losers were happier than winners both before and after the election; however, on the basis of evaluations one month after the election, there was no evidence that winners became happier than losers. Losers' happiness was 5.00 just before the election and 5.33 one month after the election, while winners' happiness was 4.10 and 4.40 before and after the election. The other study is Wilson et al. (2003), which investigated a U.S. presidential election in 2000 . They asked 52 college students about their happiness one day after Gore conceded. Bush supporters were significantly (at the $1 \%$ level) happier than Gore supporters. ${ }^{22}$ However, since they chose only students who were especially

\footnotetext{
20 According to information provided by the Republican National Committee and from administration office of the LDP, respectively.

21 Members of the LDP are required to pay 4000 yen as an annual fee, while nothing special is required for registration in the U.S.

${ }^{22}$ Since there were no significant differences in happiness between the two groups before the election, they subtracted people's initial happiness from the happiness after the election to evaluate the change.
} 
interested in politics, their significant results are not easily compared with our insignificant results.

Thus, whether an effect of the election results on happiness was established depended on when respondents were asked: in the U.S. the effect remained on the next day of the event, but didn't remain after a month. We interviewed respondents three days after the election, which is closer to Wilson et al. (2003), suggesting that Japanese are more indifferent than Americans. Of course, we should be careful because of the fact that there is discrepancy of two days. Kimball et al. (2006) found that dismay caused by Hurricane Katrina faded away in a week; therefore, the difference of two days might have resulted in different outcomes. ${ }^{23}$ Unfortunately, we have no clue as to the answer to this question.

\footnotetext{
${ }^{23}$ Whether the election attracted people's attention may be another point. Both the general election in Japan and the Bush vs. Gore struggle attracted much attention: it is not easy to say which one is more focused on by the nations.
} 


\section{References}

Frey, B. S. and A. Stutzer (2002) Happiness and Economics, Princeton UP.

Gilbert, D. T., E. C. Pinel, T. D. Wilson, and S. J. Blumberg (1998) "Immune Neglect: A Source of Durability Bias in Affective Forecasting," Journal of Personality and Social Psychology 75 (3), 617-638.

Kahneman, D., A. B. Krueger, D. A. Schkade, N. Schwarz, and A. A. Stone (2004) “A Survey Method for Characterizing Daily Life Experience: The Day Reconstruction Method," Science 306, 1776-1780.

Kimball, M. and R. Willis (2005) “Utility and Happiness,” mimeo.

Kimball, M., H. Levy, F. Ohtake, and Y. Tsutsui (2006) "Unhappiness after Hurricane Katrina,” NBER Working Paper No. 12062.

Tsutsui, Y., F. Ohtake, and S. Ikeda (2005) “The Reason Why you Are Unhappy,” ISER Discussion Paper No. 630. (In Japanese)

Wilson, T. D., J. Meyers, and D. T. Gilbert (2003) "How Happy Was I, Anyway?: A Retrospective Impact Bias,” Social Cognition 21 (6), 421-446. 
Table 1 Number of responses on each day in September survey

\begin{tabular}{lrrrrr}
\hline & total & $13-$ Sep & $14-$ Sep & $15-$ Sep & $16-$ Sep \\
count & 1399 & 1 & 149 & 192 & 183 \\
proportion & $100 \%$ & 0.1 & 10.7 & 13.7 & 13.1 \\
$(\%)$ & & & & & \\
\hline & & $17-$ Sep & $18-$ Sep & $19-$ Sep & $20-$ Sep \\
count & 327 & 353 & 190 & 4 \\
proportion & & 23.4 & 25.2 & 13.6 & 0.3 \\
$(\%)$ & & & & \\
\hline
\end{tabular}

Table 2 Number of supporters for each party

\begin{tabular}{|c|c|c|c|c|c|c|}
\hline & total & LDP & DP & Komei & Communist & SDP \\
\hline count & 1399 & 446 & 207 & 61 & 32 & 23 \\
\hline proportion & 100 & 31.9 & 14.8 & 4.4 & 2.3 & 1.6 \\
\hline \multicolumn{7}{|l|}{ (\%) } \\
\hline & & PNP & NPN & Other parties & No party & do not know \\
\hline count & & 3 & 1 & 3 & 589 & 34 \\
\hline proportion & & 0.2 & 0.1 & 0.2 & 42.1 & 2.4 \\
\hline$(\%)$ & & & & & & \\
\hline
\end{tabular}

Note: Communist stands for Japanese Communist Party, SDP = Social Democratic Party, PNP $=$ The People's New Party, NPN = New Party Nippon.

Table 3. Happiness values in September survey

\begin{tabular}{|c|c|c|c|c|c|c|c|}
\hline & total & 10 & 9 & 8 & 7 & 6 & 5 \\
\hline count & 1399 & 82 & 69 & 242 & 211 & 203 & 397 \\
\hline proportion & 100 & 5.9 & 4.9 & 17.3 & 15.1 & 14.5 & 28.4 \\
\hline \multicolumn{8}{|l|}{ (\%) } \\
\hline & & 4 & 3 & 2 & 1 & 0 & do not know \\
\hline count & & 57 & 61 & 17 & 13 & 9 & 38 \\
\hline proportion & & 4.1 & 4.4 & 1.2 & 0.9 & 0.6 & 2.7 \\
\hline (\%) & & & & & & & \\
\hline
\end{tabular}


Table 4. Estimates of equation (1)

\begin{tabular}{lrl}
\hline Variable & Coefficient & P-value \\
Constant & 2.421 & {$[.000]$} \\
$S E P$ & -0.100 & {$[.045]$} \\
OCT & -0.045 & {$[.370]$} \\
NOV & 0.028 & {$[.573]$} \\
$D E C$ & -0.073 & {$[.148]$} \\
JAN & 0.079 & {$[.112]$} \\
FEB & -0.098 & {$[.043]$} \\
DRULE & 0.130 & {$[.044]$} \\
DRULE *SEP & 0.088 & {$[.315]$} \\
DRULE *OCT & 0.038 & {$[.670]$} \\
DRULE *NOV & -0.009 & {$[.919]$} \\
DRULE *DEC & -0.039 & {$[.664]$} \\
DRULE *JAN & -0.022 & {$[.802]$} \\
DRULE *FEB & 0.046 & {$[.614]$} \\
$R^{2}$ & 0.008 & \\
number of & 8592 & \\
observations & & \\
\hline
\end{tabular}

Table 5. Estimates of $\alpha_{2}$ : change in happiness from August to September for each party

\begin{tabular}{lcrr}
\hline Party & Coefficient & \multicolumn{2}{c}{ p-value } \\
RULING PARTY & & 0.088 & {$[.315]$} \\
LDP & 0.058 & {$[.526]$} \\
Komei & 0.153 & {$[.448]$} \\
OPPOSITION PARTY & -0.026 & {$[.814]$} \\
DP & -0.012 & {$[.924]$} \\
SMALL & -0.068 & {$[.769]$} \\
SMALL cum non-cabinet supporter & -0.250 & {$[.341]$} \\
\hline
\end{tabular}

Table 6. The number of cabinet supporters in August and September

\begin{tabular}{llrrr}
\hline & \multicolumn{5}{c}{ August } & \multicolumn{2}{l}{ September } \\
& number of respondents & happiness & number of respondents & happiness \\
Pro-cabinet & 549 & 6.62 & 733 & 6.46 \\
Anti-cabinet & 493 & 6.2 & 410 & 5.95 \\
Others & 315 & 6.2 & 218 & 6.14 \\
\hline
\end{tabular}


Table 7. Characteristics of cabinet supporters

\begin{tabular}{lrr}
\hline Parameter & Estimate & P-value \\
Constant & -1.336 & {$[.000]$} \\
GOODNEWS & 0.017 & {$[.012]$} \\
DMAN & -0.057 & {$[.119]$} \\
AGE & 0.000 & {$[.929]$} \\
SCHOOL & 0.053 & {$[.044]$} \\
LARGE15CITY & 0.007 & {$[.908]$} \\
OTHERCITY & 0.027 & {$[.530]$} \\
AGRICULTURE & 0.045 & {$[.697]$} \\
OFFICE & 0.061 & {$[.266]$} \\
FIELD & 0.012 & {$[.819]$} \\
FREE_MANAGE & -0.121 & {$[.194]$} \\
HOUSEWIFE & -0.032 & {$[.573]$} \\
STUDENT & 0.123 & {$[.348]$} \\
OTHERJOB & 0.152 & {$[.011]$} \\
HOKKAIDO & -0.226 & {$[.008]$} \\
TOHOKU & 0.077 & {$[.299]$} \\
KANTO & 0.063 & {$[.265]$} \\
KEIHIN & 0.153 & {$[.043]$} \\
KOSINETU & -0.280 & {$[.001]$} \\
HOKURIKU & 0.137 & {$[.199]$} \\
TOKAI & -0.042 & {$[.509]$} \\
KINKI & 0.110 & {$[.101]$} \\
HANSHIN & 0.027 & {$[.713]$} \\
TYUGOKU & 0.047 & {$[.543]$} \\
SIKOKU & -0.118 & {$[.221]$} \\
GOODBC & 0.236 & {$[.000]$} \\
SLDP & 1.517 & {$[.000]$} \\
SDP & -0.393 & {$[.000]$} \\
SKOMEI & 1.138 & {$[.000]$} \\
SCOMMUNIST & -0.621 & {$[.000]$} \\
SSDP & -0.670 & {$[.000]$} \\
R & 0.285 & \\
number of & 8592 & \\
observations & & \\
\hline & & \\
\hline
\end{tabular}


Table 8. Significance of the rise in happiness of hypothetical pro-cabinet supporters

\begin{tabular}{lrr}
\hline Variable & Coefficient & P-value \\
$\mathrm{C}$ & 6.226 & {$[.000]$} \\
$S E P$ & -0.120 & {$[.234]$} \\
OCT & -0.092 & {$[.375]$} \\
NOV & 0.105 & {$[.307]$} \\
$D E C$ & -0.027 & {$[.793]$} \\
$J A N$ & 0.199 & {$[.050]$} \\
$F E B$ & -0.152 & {$[.130]$} \\
$A D D C A B$ & 0.415 & {$[.000]$} \\
$A D D C A B * S E P$ & 0.049 & {$[.753]$} \\
$A D D C A B * O C T$ & 0.084 & {$[.598]$} \\
$A D D C A B * N O V$ & -0.104 & {$[.515]$} \\
$A D D C A B * D E C$ & -0.278 & {$[.080]$} \\
$A D D C A B * J A N$ & -0.113 & {$[.475]$} \\
$A D D C A B * F E B$ & -0.008 & {$[.961]$} \\
$R^{2}$ & 0.011 & \\
Number of & 8592 & \\
observations & & \\
\hline
\end{tabular}

Table 9. Estimation results of equation (5)

\begin{tabular}{lrrrrrrrr}
\hline Variable & Coeff. & P-value & Coeff. & P-value & Coeff. & P-value & Coeff. & P-value \\
Constant & 6.148 & {$[.000]$} & 6.158 & {$[.000]$} & 6.148 & {$[.000]$} & 5.982 & {$[.000]$} \\
$S L D P$ & 0.289 & {$[.414]$} & & & 0.337 & {$[.003]$} & & \\
$S L D P * W L D P$ & 0.064 & {$[.887]$} & 0.411 & {$[.004]$} & & & & \\
$W L D P$ & & & & & & & 0.378 & {$[.114]$} \\
$R^{2}$ & 0.005 & & 0.005 & & 0.006 & & 0.007 & \\
Number of & 1361 & & 1361 & & 1361 & & 1361 & \\
observations & & & & & & & & \\
\hline
\end{tabular}


Figure 1. Average happiness of all respondents

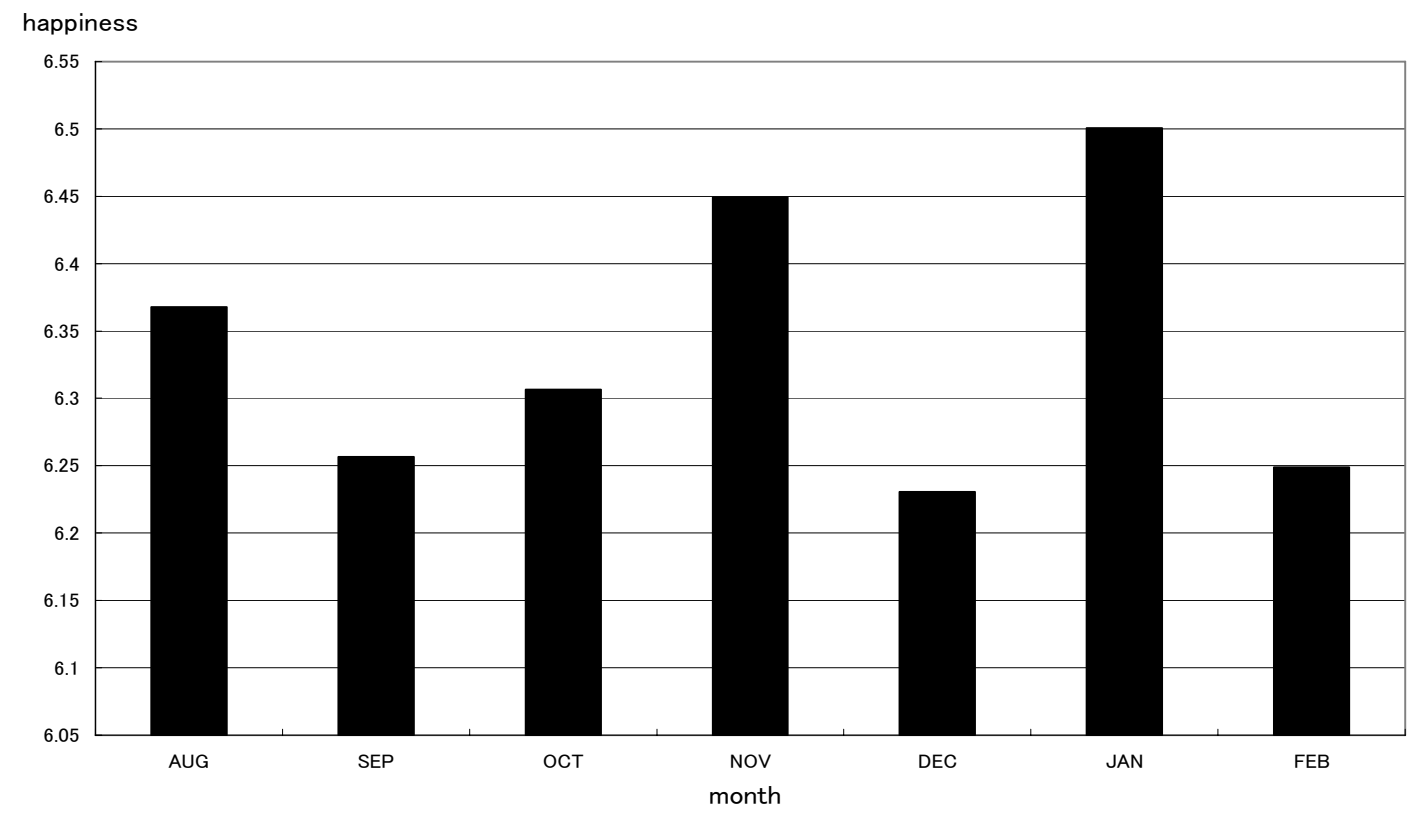

Figure 2. Normalized happiness of supporters of ruling parties, opposition parties, and those who support opposition but not the Koizumi Cabinet

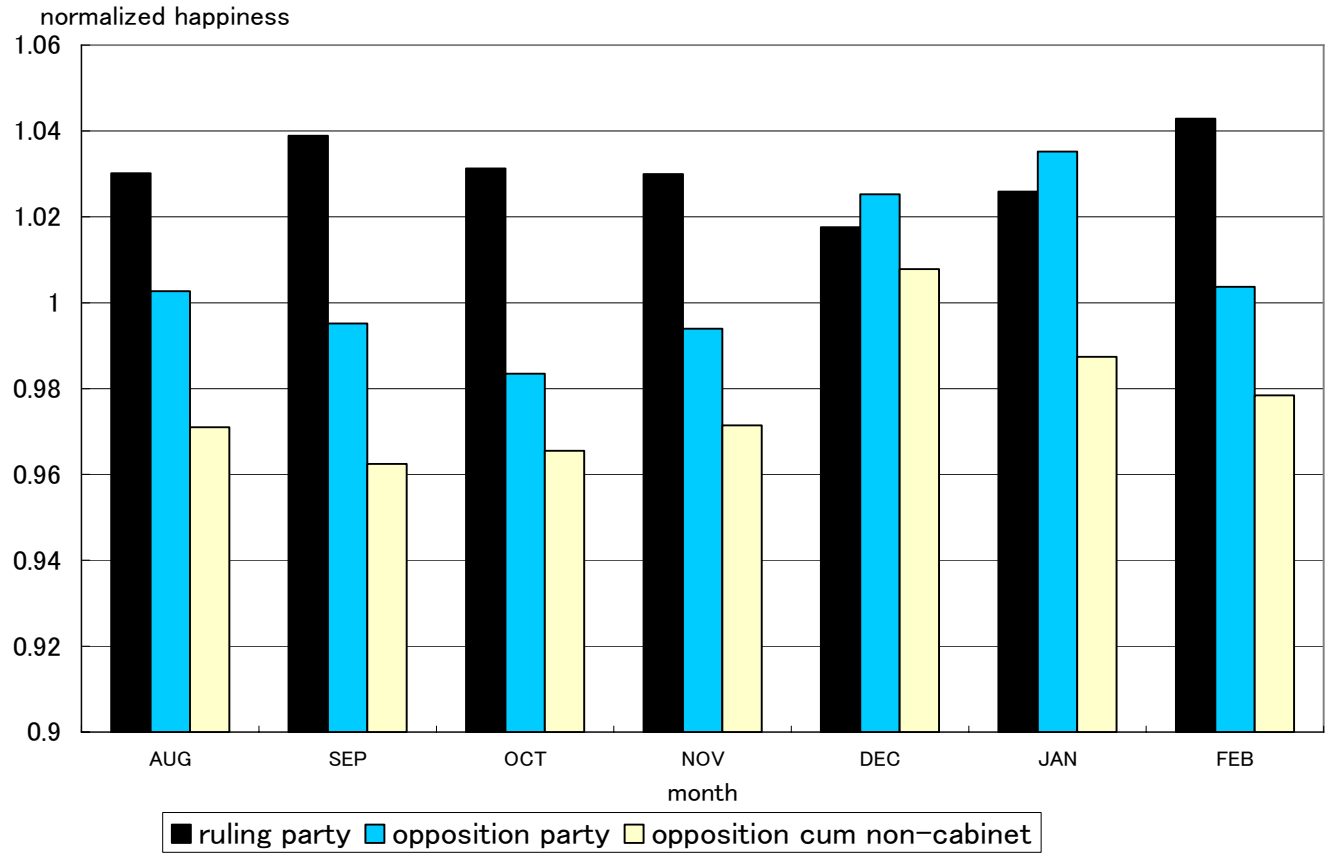

Note: Normalized happiness is (average happiness of a group)/(average happiness of the whole sample). 
Figure 3. Normalized happiness of supporters of LDP and KOMEI

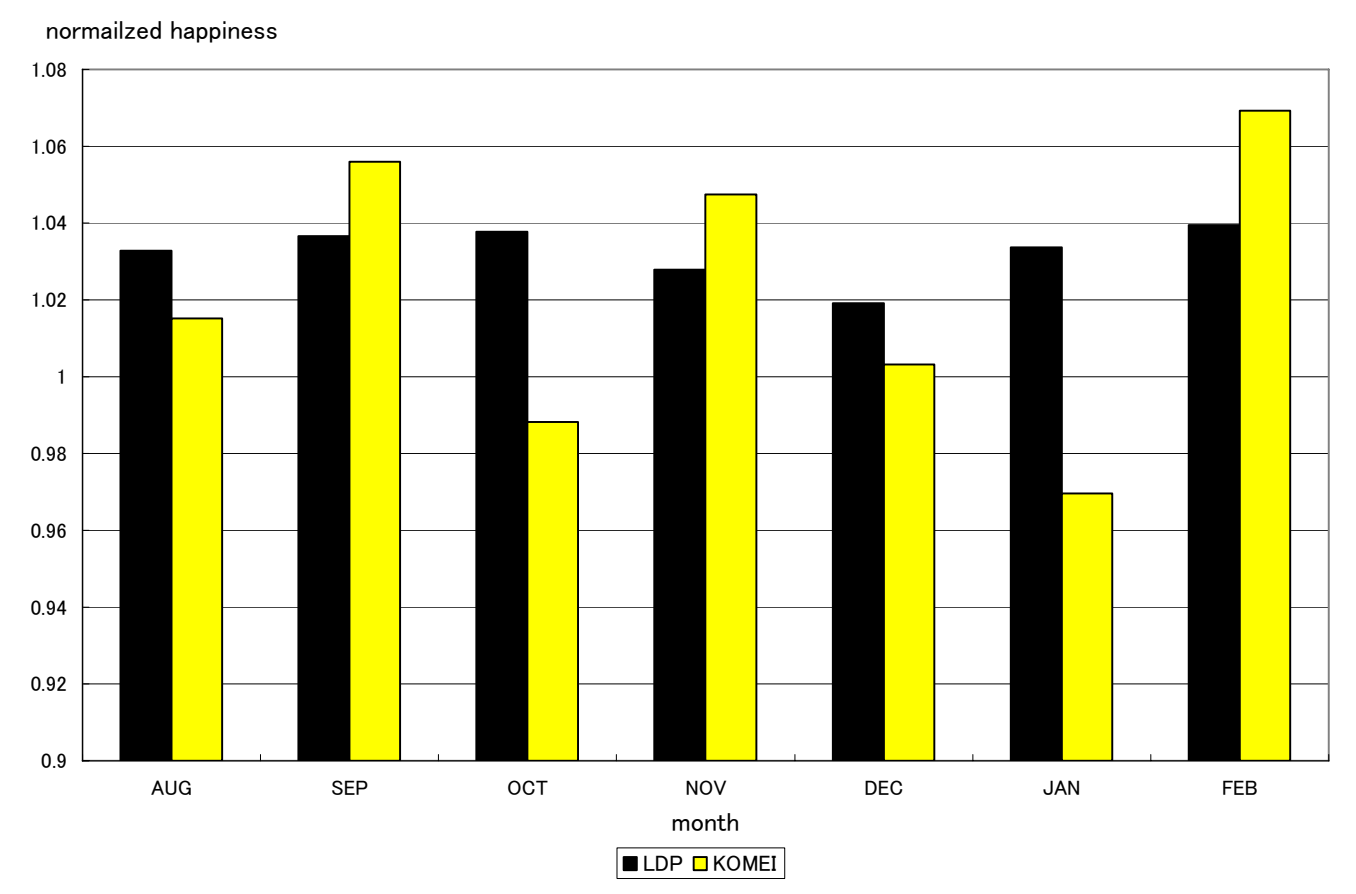

Figure 4. Normalized happiness of supporters of DP, SMALL, and SMALL cum anti-cabinet

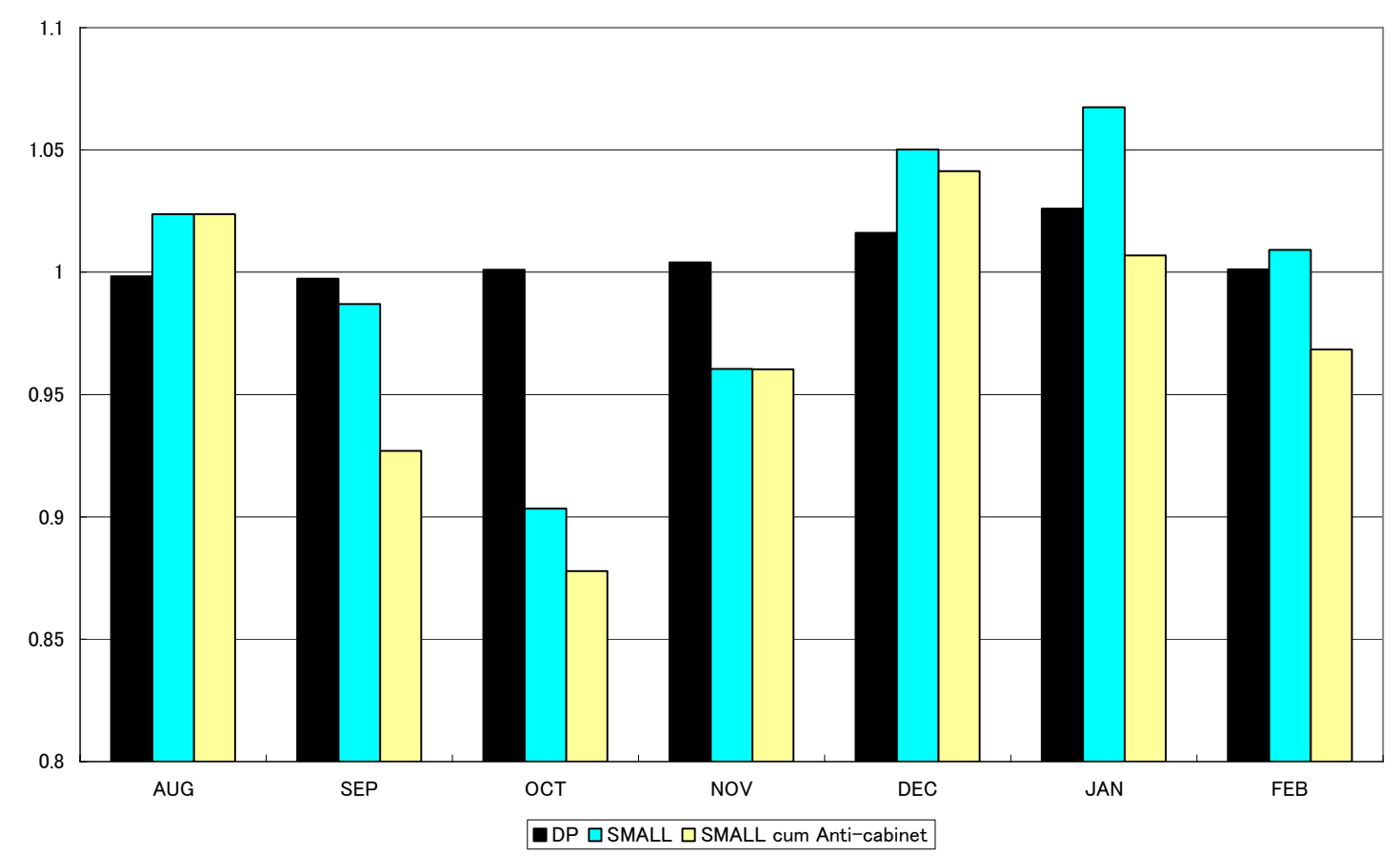


Figure 5. Normalized happiness of supporters of Komei and opposition parties for each day

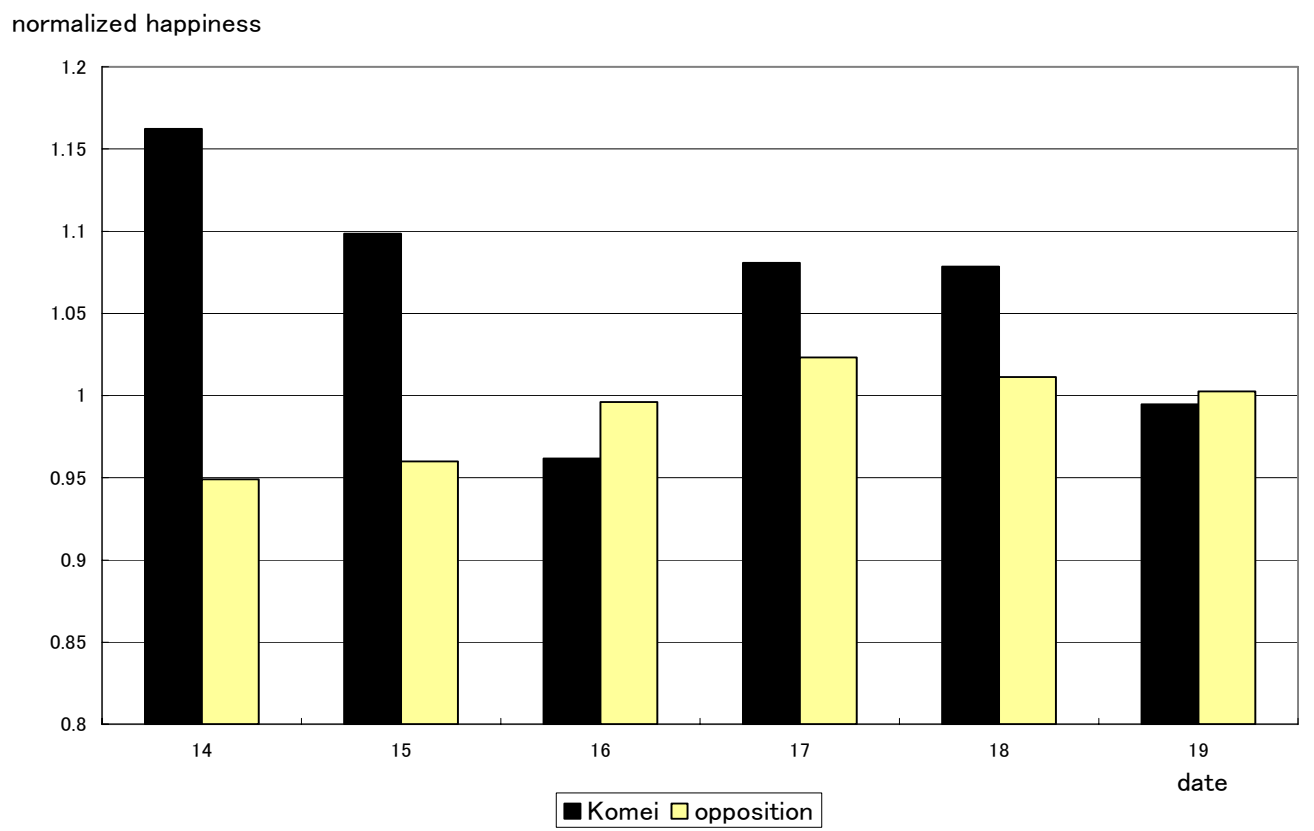

Figure 6. Normalized happiness of pro-cabinet supporters, anti-cabinet supporters, and those who answered "do not know"

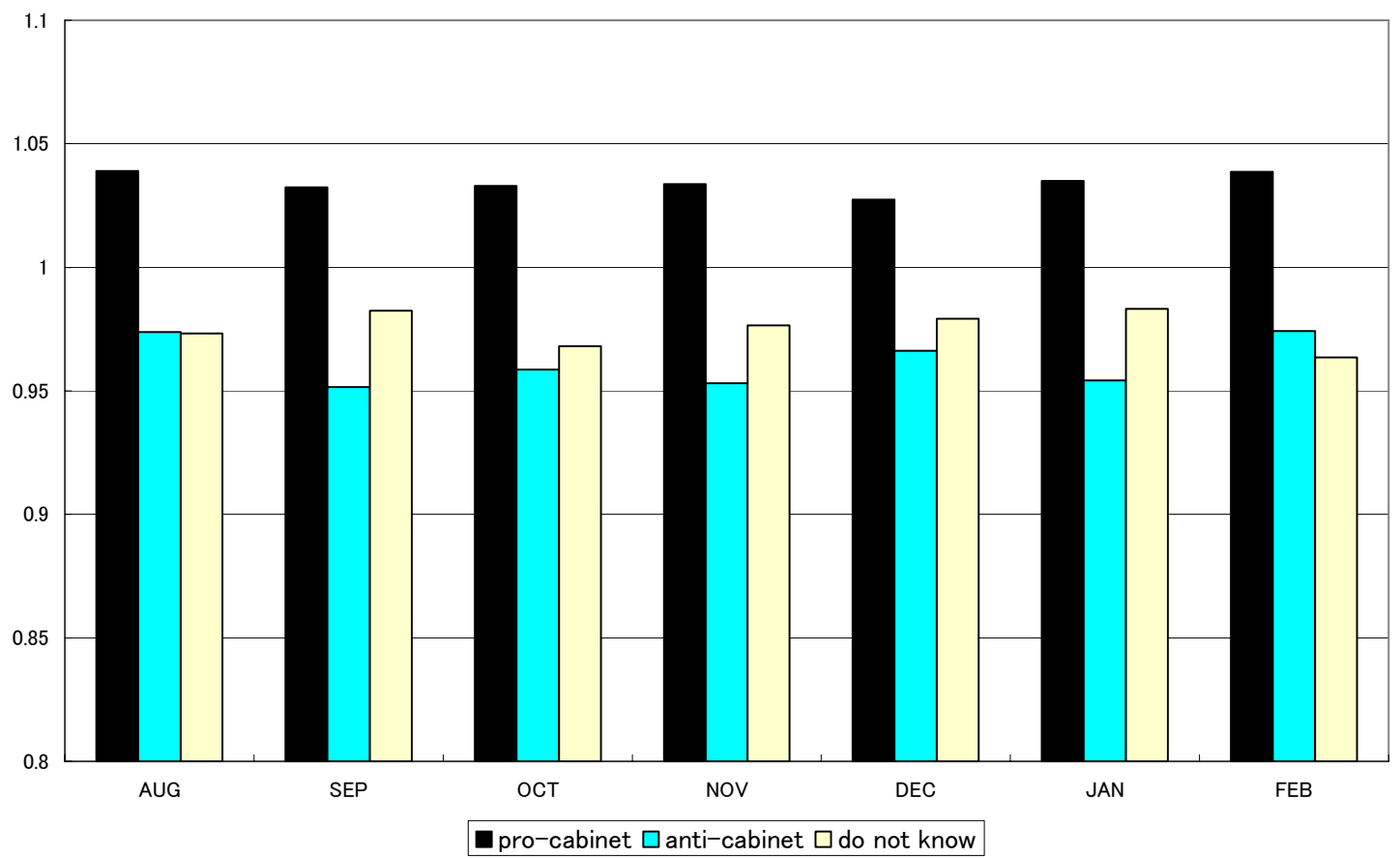


Figure 7. Normalized happiness of hypothetical pro-cabinet supporters

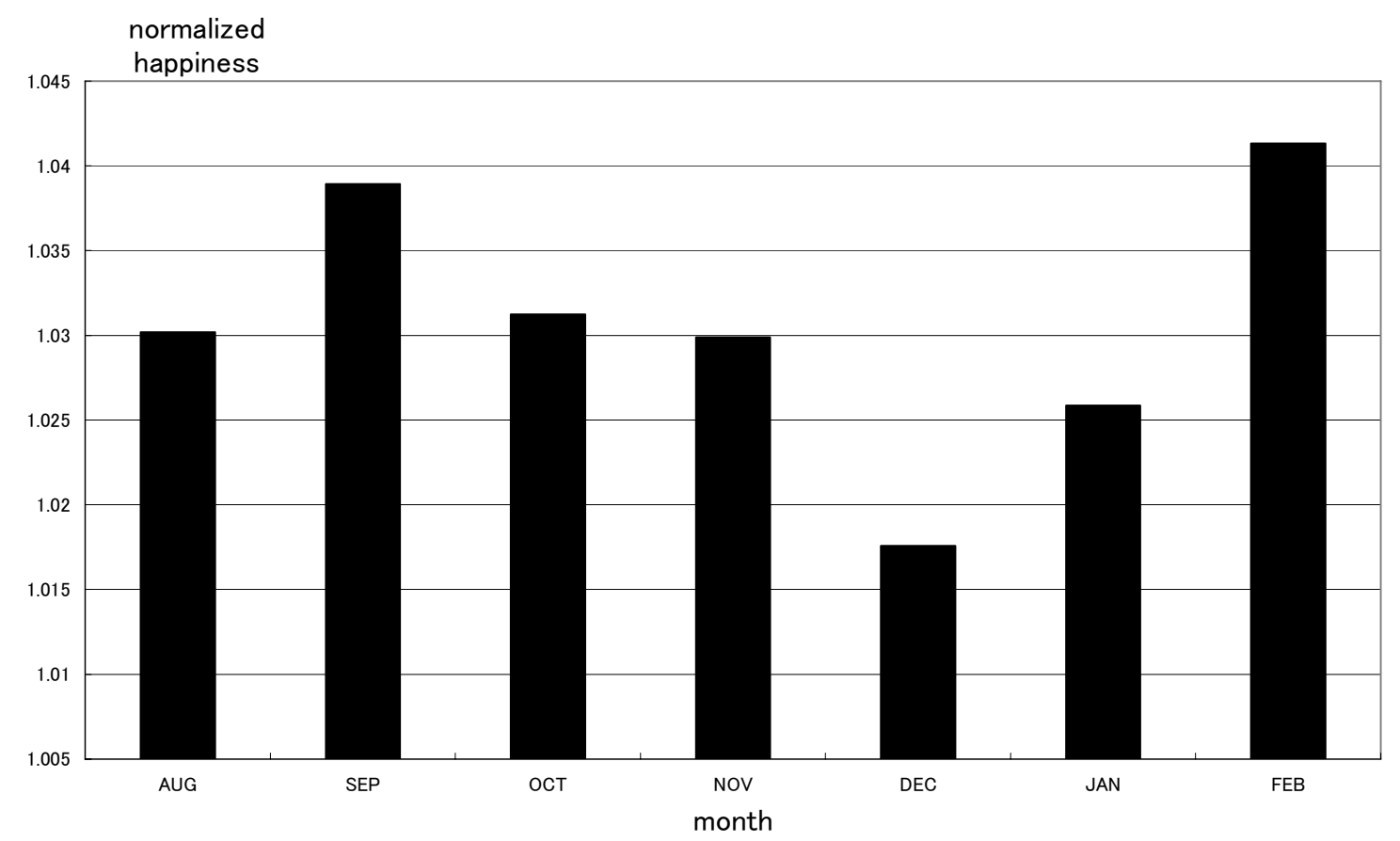




\section{Appendix}

Main events reported in the newspapers from July to October

month survey day

July

August

7/26-8/7 Six-nation talks aimed at scrapping North Korea's nuclear weapons were held

27 Space Shuttle launched

8 Simultaneous suicide bombings in London

15374 employees and contractors hired by asbestos product manufacturers have died from asbestos-related illnesses, the Ministry of Economy, Trade and Industry said in a report

5 Bills for postal privatization were approved by the House of Representatives by a majority of five votes

2 LDP (Liberal Democratic Party) announced its draft for nation's new constitution, Article 9 of the draft constitution stipulates that the Self-Defense Forces are to be maintained

5 The chair of Komei fraction at the House of Councilors opposed the postal privatization bills, massive opposition in the faction may arise

6 If the postal privatization bills are rejected at the House of Councilors, the House of Representatives will be dissolved immediately

Tokyo stock market, fall across the board on 5th Suicide website murder suspect, Maeda, was arrested on 5 th

O

7 Suicide website murder, a body found

8 The postal privatization bills were rejected at the House of Councilors; the House of Representatives was dissolved On the Tokyo financial markets, temporarily all three (stocks, yen, and bonds) fell

Suicide website murder, the third body was found

9 Upon dissolution of the House of Representatives, business world shows concern about bad effects on the economy Heizo Takenaka, Minister of Economy, Trade and Industry, declared exit from phase of leveling off for Japanese Economy 
10 Space Shuttle returned back to the Earth

10-15 Suicide website murder related articles appear in newspapers

23-31 Hurricane Katrina formed, hit Southern US

September

O

2 Hurricane in the US, one million people sought refuge

7 Typhoon No.14 killed 11 people

11 The election was held, LDP won an overwhelming victory with 296 seats in the House of Representatives

13 Six-nation talks aimed at scrapping North Korea's nuclear weapons resumed

13 Four accountants arrested on charges of falsifying accounting reports of Kanebo Ltd

14 Asahi Shimbun national survey shows the cause of victory for LDP was 58\% the Prime Minister, 18\% the party

15

16 Six-nation talks aimed at scrapping North's Korea's nuclear weapons froze as North Korea demands U.S. to provide a light-water reactor

17-26 Hurricane Rita formed, hit Southern US on 24th

18 Seiji Maehara became leader of the DP (Democratic Party of Japan)

19 Six-nation talks aimed at scrapping North Korea's nuclear weapons adopted a joint statement and the talks ended

22 The third Koizumi Cabinet was inaugurated on 21st

24 In the joint statement on 23rd, G-7 urges an increase in oil supply by oil producers

25 Expo 2005 Aichi Japan ended

26 Train-derailment accident on JR West Co. in Amagasaki, first joint memorial service was held on 25th

27 A fund headed by financier Yoshiaki Murakami has become the top shareholder in Hanshin Electric Railway Co.

29 Hannshin Tigers, became this year's Champion in the Central League Baseball

30 Osaka district court rules Prime Minister Koizumi's visits to Yasukuni Shrine unconstitutional

October

1 Japan Highway Public Corp privatized

Mitsubishi Tokyo Financial Group and UFJ Holdings integrated into Mitsubishi UFJ Financial Group

2 Series of terrorist attacks in Bali 


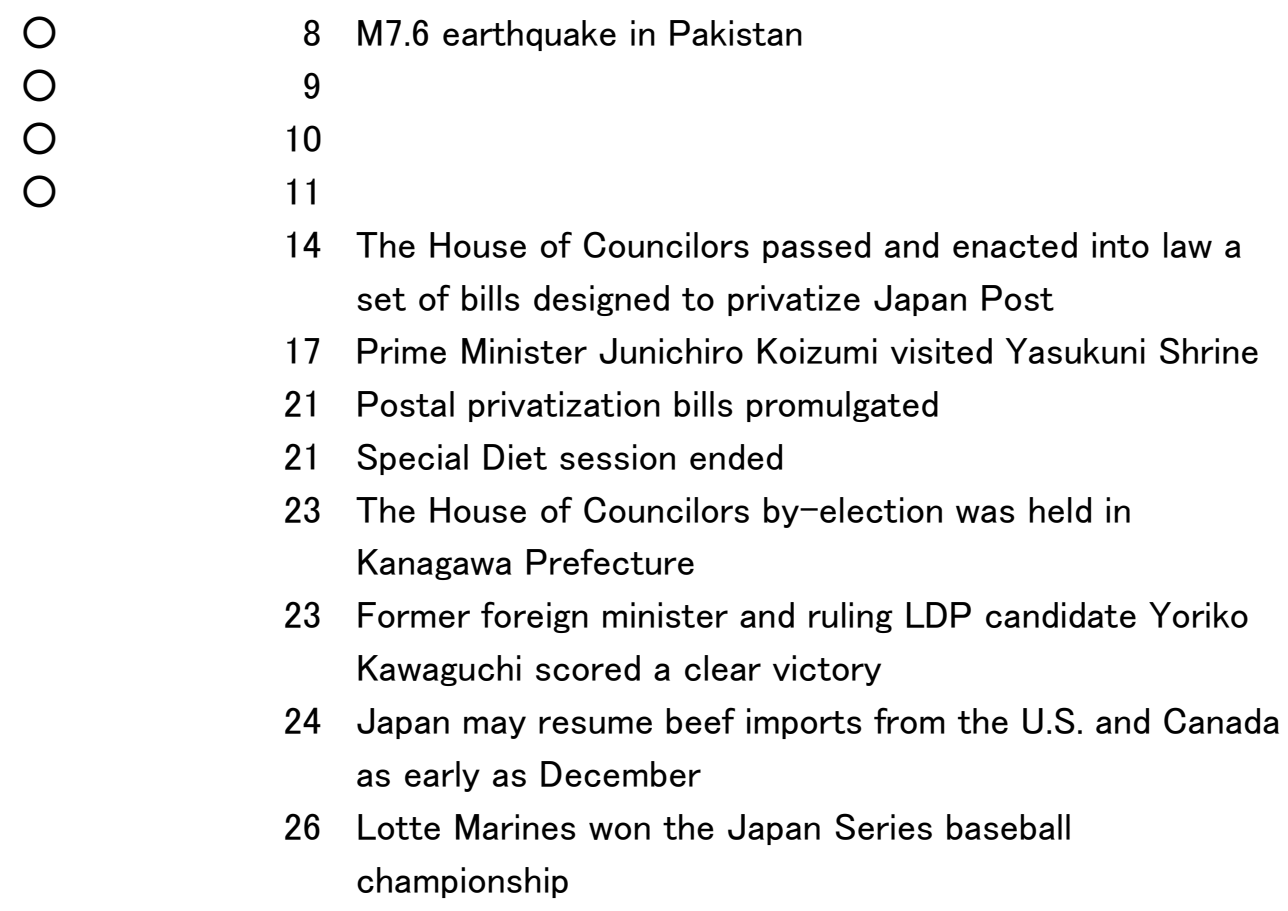

Note: $\bigcirc$ indicates the survey was conducted on that day. 